\title{
A survey of case studies in production scheduling: Analysis and perspectives
}

\author{
Helio Yochihiro Fuchigami ${ }^{\mathrm{a}, *}$, Socorro Rangel ${ }^{\mathrm{b}}$ \\ a Federal University of Goias (UFG), Faculty of Sciences and Technology (FCT), Campus Aparecida de Goiania São Paulo State University (Unesp), Institute of \\ Biosciences, Humanities and Exact Sciences (Ibilce), Campus São José do Rio Preto, Brazil \\ b São Paulo State University (Unesp), Institute of Biosciences, Humanities and Exact Sciences (Ibilce), Campus São José, Brazil
}

\section{A R T I C L E I N F O}

\section{Article history:}

Received 17 January 2017

Received in revised form 21 April 2017

Accepted 7 June 2017

Available online 22 June 2017

\section{Keywords:}

Operational research

Production scheduling

Production sequencing

Case studies

\begin{abstract}
A B S T R A C T
The problems of production scheduling and sequencing refer to decision making regarding the designation of jobs to available resources and their subsequent order to optimize pre-defined performance measures. From the early days of research in this area until this last decade, the publication of case studies has been scarce, with their frequency only increasing very recently. This survey aims to highlight practical research and case studies published in the literature in the scheduling area, identifying the main characteristics of the problems treated, trends in this research and also gaps showing potential areas for future study.
\end{abstract}

(c) 2017 Elsevier B.V. All rights reserved.

\section{Introduction}

Production scheduling is one of the most important activities of a company at the operational level for it to remain competitive in demanding consumer markets. It is related to the optimization of several performance measures, all aimed at the good functioning of the system and customer satisfaction, such as: efficient use of resources, delivery of products by given deadlines and reduction of production costs. The relevance and potential of research and application in this area is enormous for both manufacturing and service companies, which has led researchers to address the problems of production scheduling from various perspectives over the past decades.

It is well known that the first work in this area came in the 1950s, with Johnson's research publication [37] addressing the flow shop problem. Since then, many variations of the basic production scheduling problem have been formulated using different machine configurations, constraints, and optimization criteria (mono and multi-criteria). Gupta and Stafford Jr. [31] edited a special issue on flow shop problems commemorating the fiftieth anniversary of Johnson's work, stating that in this period more than 1200 studies have been published in many forms in the literature of the Operational Research area.

\footnotetext{
* Corresponding author.

E-mail address: heliofuchigami@ufg.br (H.Y. Fuchigami).
}

However, only in recent years, have here been a greater number of publications addressing practical cases of scheduling. In the 1990s, MacCarthy and Liu [52] stated that the use of the classical theory of scheduling in many production environments was minimal. In many factories, production scheduling was done by the production manager and in many departments it was delegated to managers or team leaders. In most cases, the existence of a theoretical tool that could be used in the scheduling of jobs was not valued. And, even worse, the strategic consequences of poor production scheduling in the company's overall performance were not analyzed. These authors also exposed extensive research on the gap between theory and practice of scheduling.

In the following decade, McKay et al. [56] discussed the weak connection between research results and practice, pointing to the fragility of theoretical research in the process of simplifying the real problem, disregarding, for example, work release strategies, load capacity, batch sizes, inventory levels, or mitigating situations where human intervention is required. As they suggest, research results could be much better applied, in the light of the increasing use of computer systems in industry.

Despite the hundreds of published research studies in the area, the reality of production systems is more complex, as observed by Ruiz and Maroto [70], with the distance between theory and application of existing methods being remarkable. Countering this trend of emphasizing the theory, Yagmahan and Yenisey [87] presented a review of the practice of scheduling and the recent development of both flow shop and job shop systems. In the same year, Vila and 
Pascual [84] found that most studies still considered production environments from a theoretical viewpoint, recognizing that there was still a significant gap between theory and practice, and they developed practical work addressing a hybrid flow shop problem (detailed in Section 4).

This tendency to address theoretical problems emphasizes the need to deepen the study of practical, real-life problems in order to reduce the gap between theoretical results available over six decades and their possible practical applications. The main objective of this work is to provide an in depth look at case studies published in the literature in the scheduling area identifying possible gaps that require further research. This research extends the work presented in Ref. [25].

The following sections present the theoretical basis of the work (Section 2), the methodology applied (Section 3), the description of the reviewed papers (Section 4) and the interpretation and analysis of the published articles considered (Section 5). Lastly, final considerations of the study are presented (Section 6).

\section{Theoretical framework about production scheduling}

The activity known as scheduling refers to the allocation of scarce resources to perform jobs on a time basis [8] and also to this decision-making process in both production systems and processing environments of information, transport and distribution companies, and other types of industrial services, aiming to optimize one or more objectives [60].

While it is common to give the name "sequencing problem" to scheduling studies, some authors emphasize the difference between these terms, arguing that "sequencing" is just one step of scheduling. The sequencing refers to the ordering of jobs, that is, the prioritization that establishes that one permutation of jobs is better than another. In addition to sequencing, the scheduling consists of the allocation step (or assignment of jobs to machines) and the establishment of the timing (setting when jobs start and finish). Moreover, in some systems, such as the permutation flow shop and single machine, defining the permutation of jobs i.e., sequencing the jobs corresponds exactly to the scheduling.

Morton and Pentico [58] argue that scheduling refers to the process of organizing, choosing and scheduling the resources to do all the activities necessary to meet customer demand. From this point of view, scheduling has a strategic role in the company, in contrast to many approaches that consider their importance restricted only to the shop floor.

In scheduling problems, the optimization criterion is defined in terms of one or more of several possible measures of performance. The most common are: makespan (total time to complete the schedule), flow time, earliness, tardiness, number of tardy jobs. Basically, the problems in this area can be classified as follows: single machine, parallel machines, flow shop, hybrid flow shop, job shop and open shop. The definitions of each environment can be found in Ref. [60].

In this study, the scope of the research was defined as only those published papers addressing the problem of production scheduling. However, in addition to the problems described in this classification, there are other applications that can be modelled as a scheduling problem, such as assignment problems (classes to classrooms, employees to their shift, reservations for rental agency cars), timetable problems (medical examinations, television programs, conference presentations, sports tournaments), transportation problems and project scheduling [60]. Applications also arise in task scheduling on heterogeneous cluster computing systems (e.g. [92]).

There are also integrated problems that consider making two or more simultaneous decisions, including associated scheduling decisions. For example, there is a set of problems generally known as lot-sizing and scheduling problems or simply lot-scheduling (e.g. $[61,2,23,4])$. These problems deal with the simultaneous decision of sizing production lots (lot sizing problem) and batch sequencing (production scheduling).

In the literature, scheduling problems commonly have a three field representation $\boldsymbol{\alpha}|\boldsymbol{\beta}| \boldsymbol{\gamma}$, proposed in Ref. [29]. The first field, $\boldsymbol{\alpha}$, represents the type of problem (single machine, parallel machines, flow shop, etc.), the second, $\boldsymbol{\beta}$, indicates the properties or constraint (setup time, release dates, etc.), and the third, $\boldsymbol{\gamma}$, the performance measure (makespan, flow time, etc.). New symbols can be added when the details of the representation of the problem are not found. More information on this notation can be found in Ref. [60].

\section{Research methodology}

Among the hundreds of articles published in the scheduling area each year, most use experimental research methodology, generating simulated data for both the production environment (number of stages and machines) and for the jobs (processing and setup times, delivery time etc.), the major challenge in the compilation of the articles analyzed was to identify those publications that referred to case studies.

In general, the articles used the keywords to classify the problem (such as flow shop, hybrid flow shop) and the solution technique employed (such as meta-heuristic, genetic algorithm, local search), which does not distinguish them from other research methodologies. The case studies often use more industry specific words such as food, crude-oil, electronics, clothing, aircraft, textiles, chemicals, pharmaceuticals, iron and steel, which makes a generic search more difficult. In addition, the use of the word scheduling also refers to research of integrated problems (project scheduling, lot scheduling etc.) and other situations (crew scheduling, surgery scheduling, timetable scheduling etc.) which are not the subject of this study, as indicated in Section 2. Thus, just a keyword search was not sufficient for data collection for this survey. A detailed and manual analysis was necessary. The protocol used to define the sample is described next.

From March 2014 to April 2017, searches were made at the portal Science Direct (www.sciencedirect.com), with the following criteria for inclusion and exclusion of articles in the sample:

1. Only studies reporting a scheduling problem applied to a real case, identifying the industrial sector and enabling the classification of the production environment (flow shop, job shop etc.) were included.

2. Only papers from indexed journals and peer evaluated. Thus, academic publications such as theses, dissertations and monographs, publications for scientific events, annals and abstracts for conferences and congresses, and chapters of books were all excluded.

3. Only papers written in English and with keywords in English were considered.

The literature review methodology conducted can be summarized in two stages. First, the keywords for searches were chosen, used in isolation and combined: scheduling, case study, industry and manufacturing. The first search returned thousands of articles, most research outside of the scheduling area or not including cases studies. Only the first 10 pages with 50 works per page were considered. The initial sample was formed with manual selection of articles agreeing with the criteria 1-3 for inclusion and exclusion. This step required reading the abstracts carefully and, often, it was also necessary to consult the full text of the article. 
In the second stage of searches, the oldest element of the initial sample (the Ref. [74] published in 1992) was identified. New attempts were made to find a case study published prior to that date, but without success. This defined the period spanning the publications: from 1992 to 2016. This timeline was organized into five periods: articles published up to 2000 , from 2001 to 2005 , from 2006 to 2010, from 2011 to 2015 and 2016. To avoid the bias of possible results of the searches ordered simply by the year of publication, the queries were redone for each of these established time intervals and new articles were included in the final sample, which comprises 46 papers. All 46 articles were read in full and tabulated for subsequent analysis and identification of correlations, trends and gaps indicative of potential study. The protocol adopted here is similar to that proposed in Ref. [28] which led to a sample of 33 articles.

It is important to note that some of the publications looked at in the initial search, mainly in the area of reduction of energy consumption, such as Refs. [49,75,93], state that the results were tested in real cases but without describing the company that applied them. The lack of information about the actual company means that there is no basis for comparison with other case studies, therefore, these articles were not included in the final sample now being considered.

This survey does not intend to provide an exhaustive review of the literature in order to enumerate and exhaust all published articles, but it does give an overview of the mapping of practical research in the area by a sufficiently representative sample. For example, in more general searches, one could find other works (e.g. $[91,89,42,5])$ none of them were indexed case or case study. Or find papers, like Ref. [55], that refers to case study in the title, but conducted the experimental work without real data.

\section{Description of the reviewed papers}

According to some article reviews (e.g. [24,66,69,7,1,43,67,71]) most of the research carried out in the scheduling area are experimental simulations, without the use of real data, both for the production environment (data such as number of machines and stages and flow precedence) and the products manufactured (processing and preparation times, release times and deadlines). In recent years there have been an increasing number of publications on practical work, as pointed out in Ref. [32], which provides guidelines for reducing this theory-practice gap. The authors discuss the benefits and drawbacks of existing solution methods and conclude that the available optimization tools can effectively support production systems, although there is still clear potential for improvement, especially turning academic results into industrial use.

The objective of this review is to provide an in depth look at the publications presenting case studies. The 46 articles of the sample, selected according to the protocol defined in Section 3, were organized in chronological order and their main characteristics are summarized in Table 1. For each paper, the authors, year, industrial sector, problem classification, the most relevant characteristics and the techniques used to solve the problem are given. As can be seen in this table, the oldest case study found in scheduling was the Ref. [74], which addressed a textile factory in order to minimize the maximum tardiness of jobs. A mixed integer linear programming (MILP) model and heuristic methods were proposed. Guo et al. [30], also in the textile industry, analyzed an apparel plant, proposing a MILP model and a genetic algorithm to minimize the penalties of earliness and tardiness of jobs.

The second oldest case study was by Tsubone et al. [82] in a photographic film factory, considering hundreds of end products. The performance measures considered were the ratio of setup to processing times and also the WIP (work in process). Still in the category of small items manufacture, there is the adhesive labels factory [46]. The authors proposed heuristics to minimize the maximum weighted tardiness. Bożejko et al. [12] applied tabu search algorithms for the makespan minimization in automated manufacturing lines of printed packaging.

Blömer and Günther [10] analyzed the problem in a chemical plant. The authors proposed a MILP model and also heuristics based on linear relaxation. A shampoo factory was studied in Ref. [9], which proposed several solution methods (heuristics and metaheuristics) to minimize the setup time and the maximum lateness. A variable neighbourhood search algorithm was proposed to solve a flexible flow shop problem with arrival of new jobs in a petrochemical industry [65].

One of the most researched sectors was the food industry. Vila and Pascual [83] and Kopanos et al. [41] analyzed ice cream factories. Both proposed MILP models. The first also used the metaheuristics GRASP and Simulated Annealing and the latter a linear relaxation based heuristics. Boukef et al. [11] developed a genetic algorithm for a generic agri-food factory. Parthanadee and Buddhakulsomsiri [59] used a computational simulation model with dynamic priority rules to minimize mean flow time and tardiness measurements in a real application in a canned fruit factory. Research in the bread making industry is presented in Ref. [34,33]. A MILP model was proposed in Ref. [81] to represent an optimization problem in a dairy industry, including sequence-dependent setup times, machine speed and capacity constraints.

The electronics industry was studied in five papers. In Ref. [36] a genetic algorithm to minimize the makespan for a factory of printed circuit boards is proposed; in Ref. [73] an artificial neural network and a multi-objective genetic algorithm to optimize various performance criteria, including utilization rate, average cycle time, waiting time and stock measurements, is proposed to a semiconductor chip making factory; in Refs. [18,47] computational simulation approaches are applied. A case study on production of satellite components was conducted in Ref. [63]. Several heuristics and meta-heuristics (genetic algorithm and quantum differential evolutionary algorithm) are proposed to solve a flow shop problem with position-dependent learning effect.

Four papers have addressed the furniture industry. Wilson et al. [86] developed a genetic algorithm for the programming of cutting and sawing operations. Vidal et al. [82] looked at a small producer of custom-made furniture and proposed a multi-objective evolutionary algorithm (makespan and total tardiness) and also neural network techniques to solve the problem. Gawroński [26] presented a hierarchical strategy with priority rules for minimizing setup time in a make-to-order furniture factory. Marichelvam et al. [54] proposed an improved Cuckoo Search meta-heuristic to minimize makespan in a leading furniture manufacturing company.

The pharmaceutical sector has been studied by several researchers. Boukef et al. [11] used a genetic algorithm to minimize the total cost of production. Kopanos et al. [40] propose two MILP models and heuristics based on a linear relaxation model, both methods being used to minimize the makespan and total weighted lateness. Stefansson et al. [78] developed a MILP model to minimize the total weighted tardiness.

Applications related to the steel industry were considered in three papers. Kong et al. [39] and Yang et al. [90] developed MILP models. Li et al. [45] proposed a Fruit Fly algorithm for scheduling casting. Three studies dealt with the aeronautical industry $[76,77,44]$. The first two proposed MILP models and considered the adjacency constraints, which represent cases of impediment in the execution of jobs in parallel. The last one developed a genetic algorithm to the problem. Two recent papers focused on research related to electrical energy. Chen et al. [16] proposed a MILP model and meta-heuristics to minimize the makespan in a solar cell fac- 
Table 1

(a) Summary of the case studies analyzed. (b) Summary of the case studies analyzed. (c) Summary of the case studies analyzed. (d) Summary of the case studies analyzed.(continued).

\begin{tabular}{|c|c|c|c|c|c|}
\hline Author (Year) & Industrial sector & Problem classification & Criteria & Relevant features & Solution techniques \\
\hline $\begin{array}{l}\text { Serafini and Esperanza } \\
\text { [74] }\end{array}$ & Textile industry & Flow shop & Mono & $\begin{array}{l}\text { - Minimization of maximum tardiness } \\
\text { - Minimization of makespan }\end{array}$ & $\begin{array}{l}\text { - MILP } \\
\text { - Heuristic (LP relaxation) }\end{array}$ \\
\hline Tsubone et al. [82] & Photographic film industry & $\begin{array}{l}\text { Hybrid flow shop } \\
\text { (2 stages) }\end{array}$ & Multi (bi) & $\begin{array}{l}\text { - Minimization of setup/processing times rate and } \\
\text { work in process (WIP) }\end{array}$ & - Heuristic \\
\hline Blömer and Günther [10] & Chemical industry & Hybrid flow shop & Mono & - Minimization of makespan & $\begin{array}{l}\text { - MILP } \\
\text { - Heuristic (LP relaxation) }\end{array}$ \\
\hline Jin et al. [36] & $\begin{array}{l}\text { Electronics - Printed } \\
\text { circuits factory }\end{array}$ & $\begin{array}{l}\text { Hybrid flow shop } \\
\text { (3 stages) }\end{array}$ & Mono & - Minimization of makespan & - Genetic algorithm \\
\hline Lin and Liao [46] & Sticky labels factory & $\begin{array}{l}\text { Hybrid flow shop } \\
\text { (2 stages) }\end{array}$ & Mono & $\begin{array}{l}\text { - Minimization of maximum tardiness } \\
\text { - Sequence-dependent setup times (Stage 1) } \\
\text { - Eligible machines (Stage 2) }\end{array}$ & - Heuristics \\
\hline Wilson et al. [86] & Furniture factory & $\begin{array}{l}\text { Hybrid flow shop } \\
\text { (2 stages) }\end{array}$ & Mono & $\begin{array}{l}\text { - Minimization of makespan } \\
\text { - Identical parallel machines } \\
\text { - Setup for groups of jobs }\end{array}$ & - Genetic algorithm \\
\hline Alavarez-Valdes et al. [3] & Glass factory & Flexible job shop & Multi & $\begin{array}{l}\text { - Minimization of a compound function (based on due } \\
\text { dates) } \\
\text { - No-wait constraint }\end{array}$ & - Heuristics \\
\hline Guo et al. [30] & Clothing factory & Job shop & Mono & - Minimization of early and tardy penalties & $\begin{array}{l}\text { - MILP } \\
\text { - Genetic algorithm }\end{array}$ \\
\hline Ruiz and Maroto [69] & Ceramic tile factory & Hybrid flow shop & Mono & $\begin{array}{l}\text { - Minimization of makespan } \\
\text { - Unrelated parallel machines } \\
\text { - Eligible machines } \\
\text { - Sequence-dependent setup times }\end{array}$ & - Genetic algorithm \\
\hline Boukef at al. [11] & $\begin{array}{l}\text { Pharmaceutical and } \\
\text { Agro-food industry }\end{array}$ & $\begin{array}{l}\text { Flow shop } \\
\text { ( } 2 \text { stages) }\end{array}$ & Multi & - Minimization of production costs & - Genetic algorithm \\
\hline Loukil et al. [50] & Metal foundry & Hybrid job shop & Multi & $\begin{array}{l}\text { Minimization of makespan, mean flow time, } \\
\text { maximum tardiness and mean tardiness }\end{array}$ & - Simulated annealing \\
\hline Vila and Pascual [84] & Ice cream production & $\begin{array}{l}\text { Hybrid flow shop } \\
\text { ( } 3 \text { stages) }\end{array}$ & Multi & $\begin{array}{l}\text { - Maximization of a priority function } \\
\text { - No-wait restriction } \\
\text { - Setup cost per batch }\end{array}$ & $\begin{array}{l}\text { - MILP } \\
\text { - GRASP } \\
\text { - Simulated annealing }\end{array}$ \\
\hline Kong et al. [39] & Iron and steel industry & Hybrid flow shop & Multi & - Minimization of production costs & - MILP \\
\hline Kopanos et al. [40] & Pharmaceutical industry & $\begin{array}{l}\text { Hybrid flow shop } \\
\text { (6 stages) }\end{array}$ & Multi (bi) & $\begin{array}{l}\text { - Minimization of makespan and total weighted } \\
\text { lateness }\end{array}$ & $\begin{array}{l}\text { - MILP } \\
\text { - Heuristic (MILP relaxation) }\end{array}$ \\
\hline $\begin{array}{l}\text { Parthanadee and } \\
\text { Buddhakulsomsiri [59] }\end{array}$ & Tinned fruit factory & Flow shop & Multi & $\begin{array}{l}\text { - Minimization of mean flow time, average number of } \\
\text { tardy jobs and mean tardiness } \\
\text { - Sequence-dependent setup times }\end{array}$ & $\begin{array}{l}\text { - Computational simulation of priority } \\
\text { rules }\end{array}$ \\
\hline Senties et al. [73] & $\begin{array}{l}\text { Semiconductor } \\
\text { manufacturing }\end{array}$ & Job shop & Multi & $\begin{array}{l}\text { Optimization of multicriteria (facility average } \\
\text { utilization, average cycle time, waiting time, } \\
\text { number of batches and inventory level) }\end{array}$ & $\begin{array}{l}\text { - Artificial neural network } \\
\text { - Multi-objective Genetic Algorithm }\end{array}$ \\
\hline Choi et al. [18] & Electronics (LCD screens) & $\begin{array}{l}\text { Hybrid flow shop } \\
\text { ( } 5 \text { stages) }\end{array}$ & Multi & $\begin{array}{l}\text { - Maximization of system utilization } \\
\text { - Minimization of mean flow time, mean tardiness } \\
\text { and number of tardy jobs } \\
\text { - Reentrant flow }\end{array}$ & $\begin{array}{l}\text { - Decision tree mechanism } \\
\text { - Computational simulation of priority } \\
\text { rules }\end{array}$ \\
\hline
\end{tabular}



ines (printed packages) Solar cell production

Flexible job shop

\section{Car factory}

Aeronautics industry

Bread making

Steelmaking casting

Furniture factory
Dynamic job shop

Hybrid flow shop (3 stages)

Hybrid flow shop

Hybrid flow shop (6 stages)

Job shop

Job shop

\section{Multi}

Mon

Mono

Mono

Mono

Multi (bi)
Minimization of setup time and maximum latenes - Buffer with limited capacity (no-wait constraint)

Minimization of total weighted tardiness

- Sequence-dependent setup times

- Minimization of makespan

Adjacent restrictions (constraint on jobs done in parallel)

- Minimization of makespan and total tardiness

- Minimization of makespan, total tardiness and total idle time

- Reentrant flow

- Minimization of setup time

- Sequence-dependent setup times

- Minimization of makespan

- Sequence-dependent setup times

- Minimization of makespan

- Minimization of makespan

- Eligible machines (Stage 1)

- Identical parallel machines (Stages 2-4)

- Setup independent (Stage 5) and dependent (Stage 6)

- Minimization of a compound function of weighted costs and tardiness

- Minimization of makespan and amount of workers - Adjacency constraint (constraint on jobs done in parallel)

- Minimization of makespan and machine idle time - No-wait constraint

Minimization of makespan

- Machine setup times and time of transfer between stages

- Minimization of makespan
- MILP

- MILP

- Multi-objective Evolutionary Algorithm

- Neural networks

- Greedy algorithm

- Ant Colony Optimization with

Simulated Annealing

- Heuristic based on an assignment problem

- Genetic Algorithm

- Hierarchical strategy with priority rules

- MILP

- Heurisitc (MILP relaxation)

- Tabu Search Algorithm

- MILP

- Variable Neighbourhood Search

- Genetic algorithm and local search

- MILP

- Genetic algorithm

- Ant colony

- Random search

- Fruit Fly Algorithm

- Cuckoo Search Algorithm 


\begin{tabular}{|c|c|c|c|c|c|}
\hline Author (Year) & Industrial sector & Problem classification & Criteria & Relevant features & Solution techniques \\
\hline Hastuti et al. [33] & Bread making & Flow shop & Mono & - Minimization of makespan & - MILP \\
\hline Jun and Park [38] & Electricity Transformers & $\begin{array}{l}\text { Hybrid flow shop } \\
\text { (2 stages) }\end{array}$ & Mono & $\begin{array}{l}\text { - Minimization of total tardiness } \\
\text { - Unrelated parallel machines } \\
\text { - Different release dates }\end{array}$ & - Hybrid Genetic Algorithm \\
\hline Lin and Chen [47] & Semiconductors & Hybrid flow shop & Mono & - Minimization of flow time & $\begin{array}{l}\text { - Computational simulation } \\
\text { - Genetic Algorithm }\end{array}$ \\
\hline Rahman et al. [64] & Sanitary equipment & Permutation flow shop & Mono & $\begin{array}{l}\text { - Maximization of number of acceptable jobs } \\
\text { - Dynamic arrival of jobs }\end{array}$ & - Genetic Algorithm \\
\hline Rossi et al. [68] & Bespoke tailoring & $\begin{array}{l}\text { Hybrid shop (flow shop } \\
\text { and open shop) }\end{array}$ & Mono & - Minimization of makespan & $\begin{array}{l}\text { - MILP } \\
\text { - Constructive Algorithm }\end{array}$ \\
\hline Yang et al. [90] & Byproduct gas in steel plant & Hybrid flow shop & Mono & $\begin{array}{l}\text { Minimization of penalty costs of gases emission, } \\
\text { gases deviation from normal amount, gasholder } \\
\text { levels and boilers }\end{array}$ & - MILP \\
\hline Che et al. [14] & $\begin{array}{l}\text { Manufacturing plant of } \\
\text { parts for metro }\end{array}$ & Single machine & Mono & - Minimization of total electricity cost & $\begin{array}{l}\text { - MILP } \\
\text { - Greedy insertion heuristic }\end{array}$ \\
\hline Eddaly et al. [21] & Sanitary equipments & Flow shop & Mono & $\begin{array}{l}\text { - Minimization of makespan } \\
\text { - Blocking constraint }\end{array}$ & - Particle Swarm Optimization \\
\hline Gedik et al. [27] & $\begin{array}{l}\text { Inland waterways } \\
\text { infrastructure maintenance }\end{array}$ & $\begin{array}{l}\text { Unrelated parallel } \\
\text { machines }\end{array}$ & Mono & $\begin{array}{l}\text { - Maximization of total profit (each job has a profit } \\
\text { and a cost of production) } \\
\text { - Sequence-dependent setup times } \\
\text { - Job availability intervals }\end{array}$ & $\begin{array}{l}\text { - Constraint Programming } \\
\text { - Logic-based Benders Algorithm }\end{array}$ \\
\hline Li et al. [44] & Aero engine manufacturing & Job shop & Multi (bi) & $\begin{array}{l}\text { - Minimization of makespan and production costs } \\
\text { - Dual resource constrained }\end{array}$ & - Genetic Algorithm \\
\hline Qin et al. [63] & Satellite production & Permutation flow shop & Mono & $\begin{array}{l}\text { - Minimization of makespan, total completion time, } \\
\text { total weighted completion time and maximum } \\
\text { lateness } \\
\text { - Learning effect } \\
\text { - Group technology }\end{array}$ & $\begin{array}{l}\text { - Genetic Algorithm } \\
\text { - Differential Evolutionary Algorithm }\end{array}$ \\
\hline $\begin{array}{l}\text { Rahmani and } \\
\text { Ramezanian [65] }\end{array}$ & Petrochemical industry & Hybrid flow shop & Multi & $\begin{array}{l}\text { - Minimization of total weighted tardiness } \\
\text { - Maximization of stability of schedule and resistance } \\
\text { to change } \\
\text { - Arrival of new jobs }\end{array}$ & - Variable Neighborhood Search \\
\hline Touil et al. [81] & Dairy industry & Hybrid flow shop & Mono & $\begin{array}{l}\text { - Minimization of makespan } \\
\text { - Sequence-dependent setup } \\
\text { - Machine speed } \\
\text { - Batch processing }\end{array}$ & - MILP \\
\hline Wang et al. [85] & $\begin{array}{l}\text { Glass manufacturing } \\
\text { company }\end{array}$ & Single machine & Multi (bi) & $\begin{array}{l}\text { - Minimization of makespan and total energy costs } \\
\text { - Batch processing }\end{array}$ & $\begin{array}{l}\text { - MILP } \\
\text { - Heuristics }\end{array}$ \\
\hline Yan et al. [88] & Machining center & $\begin{array}{l}\text { Hybrid flow shop } \\
\text { (4 stages) }\end{array}$ & Multi (bi) & $\begin{array}{l}\text { - Minimization of makespan and total energy } \\
\text { consumption }\end{array}$ & - Genetic Algorithm \\
\hline
\end{tabular}




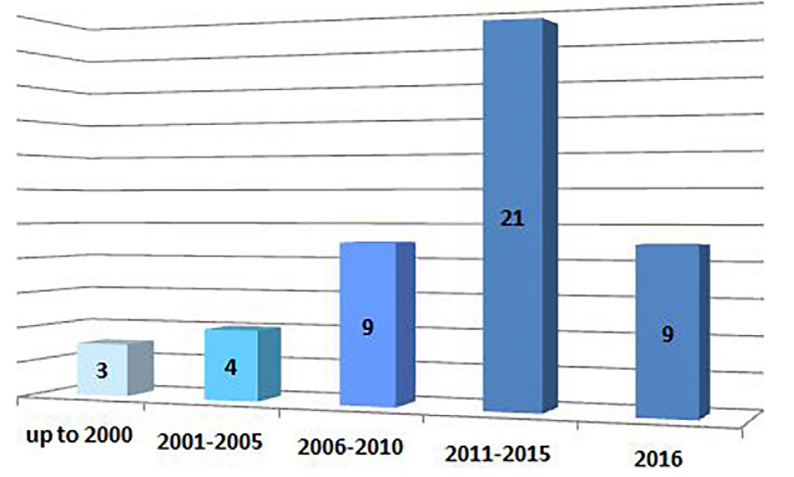

Fig. 1. Number of papers by date.

tory. And Jun and Park [38] applied a hybrid genetic algorithm in an energy transformer factory.

In the ceramic and glass sector, Ruiz and Maroto [70] developed a genetic algorithm to minimize the makespan in a ceramic tile factory, considering various realistic constraints such as different resources working in parallel at various stages, eligibility of machines and sequence-dependent setup times. For glass factories, Alvarez-Valdes et al. [3] proposed a heuristic to minimize a multiobjective lateness function and Wang et al. [85] formulated a MILP model for a bi-objective single machine batch problem to minimize makespan and total energy cost.

Manufacturing plants for machined items was addressed in Ref. [14,88]. In Ref. [14], the manufacturer receives an order of processing annular parts for a metro construction project. A new continuous-time MILP model and an efficient greedy insertion heurist were proposed. Yan et al. [88] employed a genetic algorithm to optimize makespan and total energy consumption in a machining center modelled as a flexible flow shop problem.

In the sector of sanitary equipments, Rahman et al. [64] applied a genetic algorithm and Eddaly et al. [21] developed hybrid combinatorial particle swarm optimization algorithm. Five more industrial sectors are included in the sample with only one paper for each sector. Loukil et al. [50] developed a Simulated Annealing algorithm to optimize a multi-objective problem considering makespan, mean flow time, maximum tardiness and mean tardiness for a plant specialized in brass product. A weapons factory was addressed in Ref. [15] and the problem was solved by a genetic algorithm minimizing the makespan, total tardiness and the total idle time. Zhang et al. [94] also used meta-heuristics to solve the problem of minimizing a function composed of production costs and tardiness in a car plant. Rossi et al. [68] developed a MILP model and constructive heuristics for a high-fashion industry. Gedik et al. [27] proposed a constraint programming model and logic-based Benders algorithms to optimize the inland waterway infrastructure maintenance operations conducted by the U.S. Army Corps of Engineers. They take into account constraints such as environmental windows, dredge resource cost and availability, and sequence dependent travel times.

\section{Interpretation and analysis of results}

In a global quantitative analysis, Fig. 1 shows the distribution of the number of papers analyzed divided into five time periods. The 46 articles considered span 25 years, from 1992 to 2016 . From Fig. 1 , it is possible to clearly see the increasing proportion of publications in case studies in the field of production planning, especially in recent years.

The detail of the number of papers per year, with the respective frequency, is shown in Table 2. For better visualization, Table 2 shows only the years in which papers were published. For exam-
Table 2

Number of papers (and percentage) per year.

\begin{tabular}{lll}
\hline Year & Number & Percentage \\
\hline 1992 & 1 & 2.17 \\
1993 & 1 & 2.17 \\
1998 & 1 & 2.17 \\
2002 & 1 & 2.17 \\
2003 & 1 & 2.17 \\
2004 & 1 & 2.17 \\
2005 & 1 & 2.17 \\
2006 & 2 & 4.35 \\
2007 & 2 & 4.35 \\
2009 & 1 & 2.17 \\
2010 & 4 & 8.70 \\
2011 & 4 & 8.70 \\
2012 & 4 & 8.70 \\
2013 & 3 & 6.52 \\
2014 & 4 & 8.70 \\
2015 & 6 & 13.04 \\
2016 & 9 & 19.58 \\
Total & 46 & $\mathbf{1 0 0 . 0 0}$ \\
\hline
\end{tabular}

Table 3

Number of papers per industrial sector (in descending order of frequency).

\begin{tabular}{lll}
\hline Sector & Number & Percentage \\
\hline Food & 7 & 14.90 \\
Electronics & 5 & 10.64 \\
Furniture & 4 & 8.51 \\
Iron and steel & 4 & 8.51 \\
Pharmaceuticals & 3 & 6.38 \\
Printed items & 3 & 6.38 \\
Textiles and clothing & 3 & 6.38 \\
Chemical & 3 & 6.38 \\
Aeronautic & 3 & 6.38 \\
Ceramics and glass & 3 & 6.38 \\
Others & 8 & 19.16 \\
Total & $\mathbf{4 7}$ & $\mathbf{1 0 0 . 0 0}$ \\
\hline
\end{tabular}

ple, in the sample no papers were published in 1994, so this year is omitted. A more detailed examination of Table 2 confirms the earlier inference of the higher concentration of case study publications in recent years when compared to earlier periods.

Another finding of this research is that many intermittent production systems can be modelled and scheduled using optimization methods from the production scheduling area. There are applications in basic industries, processing industries and assembling industries [72,13]. Basic industries are companies or industrial sectors that feed other companies or sectors, operating, for example, in the extraction of minerals and in the production of electric energy and steel. The latter was considered in Refs. [39,90]. Processing industries refer to the raw material transformation sector for goods, including capital goods such as machine tools and auto parts, and consumer goods such as clothing and food. Examples of case studies in processing industries are those described in Refs. $[82,86,84,59,41,34,54,33,14,21,81]$. The assembling industries are those companies or industrial sectors that carry out the final assembly of a set of parts supplied by other factories, thus concluding a manufacturing process that covers several production units, as is the case in the production of aircraft, automobiles, electronic devices, computers, amongst others, and these were studied in Refs. $[18,77,94,16,76,44,63]$.

Table 3 shows the numbers of published papers, in descending order of frequency, according to different industrial sectors. The total number of case studies is 47 , higher than the number of papers analyzed, because Ref. [11] addressed two industries from different sectors. The most studied sector was food, with $14.90 \%$ of the cases (seven published papers). Next came the electronics, with $10.64 \%$ (five cases), and furniture and iron and steel sectors, with $8.51 \%$ of the cases (four papers each). And then the sectors: pharmaceuti- 


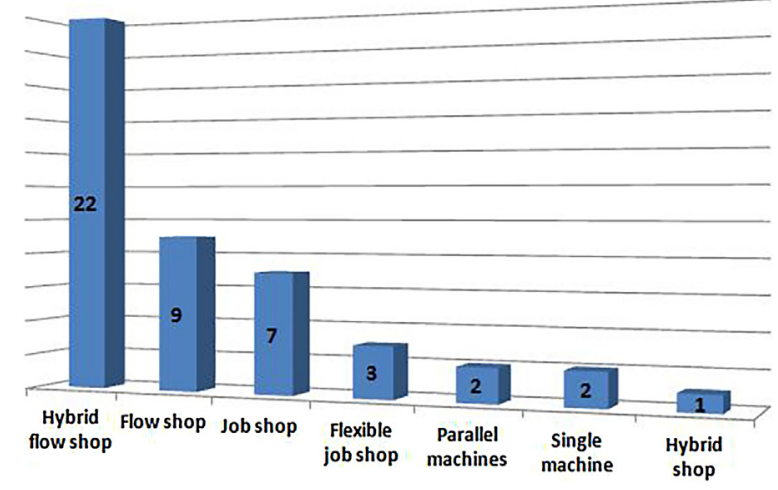

Fig. 2. Number of papers by scheduling problem.

cals, printed items, textiles and clothing, chemical, aeronautic and ceramic and glass, with $6.38 \%$ of papers (three cases each). Other less representative sectors make up together $19.16 \%$.

According to the classification of scheduling problems, the type most discussed was the hybrid flow shop, in 22 cases or $47.83 \%$ of the work, as can be seen in Fig. 2. Next, were the flow shop systems in 9 cases or $19.57 \%$ of the papers, and job shop, in 7 cases, or $15.22 \%$ of the total.

Considering together flow shop and hybrid flow shop, the percentage becomes $67.39 \%$ ( 29 cases), showing the high number of manufacturing layouts following a unidirectional flow through the production stages. Grouping job shop and flexible job shop, the frequency reaches $21.74 \%$ ( 10 cases).

The problem of parallel machines with a single stage of production was found in only two studies (4.35\% of cases). This environment is relatively frequent in experimental research, as can be seen in the reviews [17,57]. According to the sample it has not been fully explored in case studies, indicating potential for further research. The most simple production system, the single machine problem, also appeared in just two recent papers (4.35\% of cases). The hybrid shop problem is quite unusual in the scheduling literature. It is defined as the combination of flow shop and open shop and it was found in only one case study analyzed here $(2.17 \%$ of cases).

With regard to the performance measures, as well as in experimentally simulated research, the most used criterion was the makespan or a related function, found in $54.35 \%$ of the papers. Then came the measures related to tardiness in $26.09 \%$ of the sample. Less frequent measures were the ones related to production costs $(15.22 \%)$, minimizing the mean flow time (10.87\%), lateness (8.70\%), total setup time (6.52\%), electricity cost (6.52\%) and idle time (4.35\%).

As expected, there are several papers addressing multiple criteria optimization that best meet the objectives of the companies, as they often seek to optimize more than one measure at the same time. Fig. 3 shows the percentage of papers for each type of problem. In the sample, the work with multi-criteria objective functions (two or more measures) made up $43.48 \%$. Separating the data into three categories: mono-criterion, bi-criteria and multicriteria (with three or more measures), 56.52\% of searches are mono-criterion, studies with three or more criteria account for $23.91 \%$ and those with two performance measures are only $19.57 \%$ of the sample.

Regarding the solution techniques that were used, Fig. 4 details the respective numbers of papers for each kind of method used. As there are papers that used more than one technique, the sum of the column values exceeds the total of forty-eight articles. Separating the methods by "exact" (in this case, only MILP) and "non-exact"

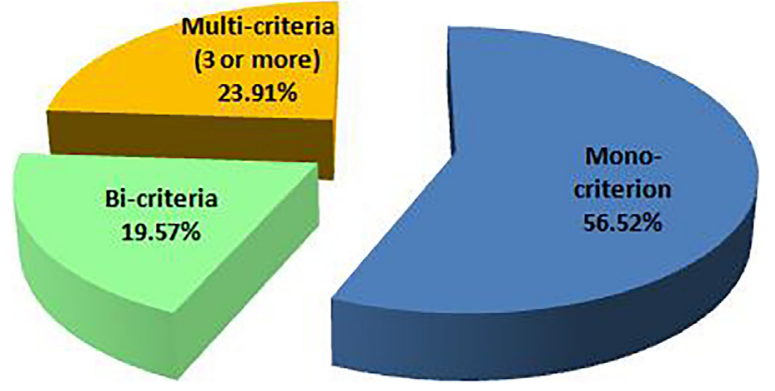

Fig. 3. Percentage of papers by number of criteria in the objective function.

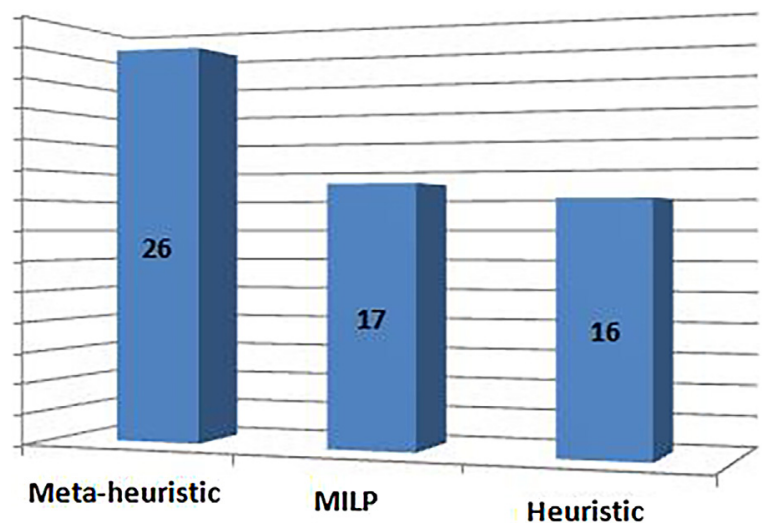

Fig. 4. Number of papers by solving technique.

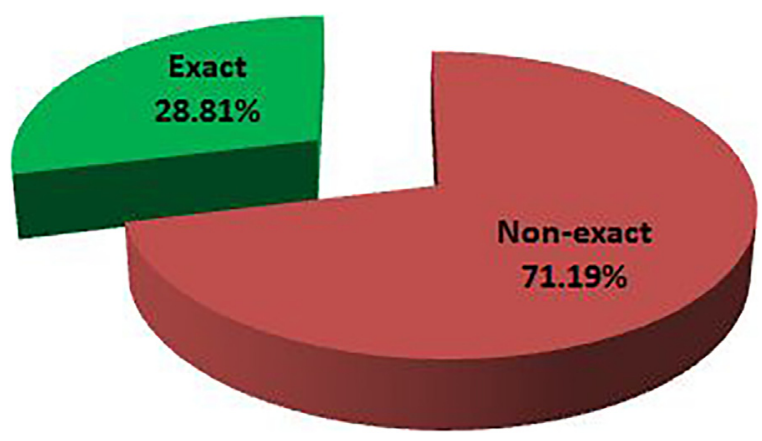

Fig. 5. Percentage of papers by solution technique.

(heuristics and meta-heuristics) gives the pie chart with the percentages shown in Fig. 5.

As can be seen in Fig. 4, more than half of the papers (26 cases) use meta-heuristics for solving the problem, i.e. $68.42 \%$ of the papers. Then came the Mixed Integer Linear Programming models (17 cases), i.e. $44.74 \%$ of the studies, and heuristics (16 cases), including computer simulations and priority rules, with $42.11 \%$. Besides the mathematical models (MILP), we found no case study whose solution was obtained by another exact solution method, such as a specific branch-and-bound method or using dynamic programming.

In the 26 studies using meta-heuristics, 32 different algorithms were used, as can be seen in Table 4. Almost half the applied metaheuristics opted for genetic algorithms (46.88\% of cases), proving their popularity and effectiveness also in the practical scheduling problems. Then, however with a big difference in the frequency of use, were the Simulated Annealing algorithm, with $9.38 \%$. The techniques Neural networks, Ant Colony, Evolutionary algorithm, Variable Neighborhood Search and Particle Swarm Optimization, all employed in two papers, represent $6.25 \%$. The other meta- 
Table 4

Number of papers using meta-heuristics (in decreasing order of frequency).

\begin{tabular}{lll}
\hline Meta-heuristics & Amount & Percentage \\
\hline Genetic algorithm & 15 & 46.88 \\
Simulated Annealing & 3 & 9.38 \\
Neural networks & 2 & 6.25 \\
Ant Colony & 2 & 6.25 \\
Evolutionary algorithm & 2 & 6.25 \\
Variable Neighborhood Search & 2 & 6.25 \\
Particle Swarm Optimization & 2 & 6.25 \\
GRASP & 1 & 3.13 \\
Tabu search & 1 & 3.13 \\
Fruit Fly & 1 & 3.13 \\
Cuckoo search & 1 & 3.13 \\
Total & $\mathbf{3 2}$ & $\mathbf{1 0 0 . 0 0}$ \\
\hline
\end{tabular}

Table 5

Number of papers with explicit constraints on the problem (in decreasing order of frequency).

\begin{tabular}{lll}
\hline Constraint & Number & Percentage \\
\hline Setup times & 14 & 42.42 \\
No-wait & 4 & 12.13 \\
Eligible machines & 3 & 9.09 \\
Release/dynamical arrival & 3 & 9.09 \\
Batch processing & 2 & 6.06 \\
Re-entrant flow & 2 & 6.06 \\
Adjacency & 2 & 6.06 \\
Blocking & 1 & 3.03 \\
Job availability intervals & 1 & 3.03 \\
Learning effect & 1 & 3.03 \\
Total & $\mathbf{3 3}$ & $\mathbf{1 0 0 . 0 0}$ \\
\hline
\end{tabular}

heuristics - GRASP, Tabu search, Fruit Fly and Cuckoo search appeared in just one paper each (3.13\%).

Given the considerable percentage difference between the exact and non-exact methods, and the wide variety of heuristics and meta-heuristics that have been used, there is, therefore, great potential for more research on exact methods, whether it is MILP models or other methods like branch-and-bound. It should be noted that the same specific problem can be solved by both exact and non-exact methods, which further underscores the possibility of exploitation of different methods.

In general, because the papers considered in this review are case studies, the authors clearly sought to incorporate very realistic features of the work environment, object of the analysis. Particularly interesting, for example, is the explicit treatment of setup times, i.e. they are treated separately from the job processing times in quite a number of studies [82,46,86,70,84,59,78,9,41,26,16,45,27,81].

When jobs are to be processed with no waiting between production stages, a no-wait constraint is used, and this is present in the studies $[3,84,9,34]$. The presence of eligible machines (resources available in a production stage but that can only handle a specific set of jobs) was considered in $[46,70,16]$. Different release date constraints and dynamic arrival of jobs was discussed in [38] and in $[64,65]$, respectively. Batch processing scheduling problems appeared in $[81,85]$. The possibility of a processed job returning to a previous stage (re-entrant flow) was found in $[18,15]$. The adjacent constraint (i.e., the impediment of execution of jobs in parallel) is present in $[77,76]$. Blocking constraint (when intermediate storage is not allowed) was considered in [21]. Presence of job availabilities intervals (the times when job processing is permitted) was found in [27]. The learning effect (when the processing time depends on the job position in the sequence) was studied in [63]. Table 5 summarizes the number of studies that addressed each of these outstanding constraints.

A complementary analysis can be done about the country of origin of the research through the information as declared by their authors. Table 6 provides a geographical-temporal mapping of researchers of the case studies involving production scheduling, i.e., the distribution of researchers from each country per year, in descending order of the total frequency. The numbers of the table refer to the number of authors (not papers) and the country of origin.

As can be seen in Table 6, of the 25 countries, the three of them with the highest numbers of researchers were: China with 28 authors (by far, in the first place), Spain with 17 authors and Taiwan with 13 authors. Brazil is in sixth place with 7 authors, after France and USA (both with 10 authors) and drawing with Japan (also with 7 authors). Most of the case studies were published more recently, after 2005, as can be also seen in Table 2. Moreover, the earliest research (pre 2005) was conducted by authors of only five countries: Taiwan, Japan, Germany, Italy and USA.

A historical survey, presented by Potts and Strusevich [62], of the characteristics of research into production scheduling in each of the five decades since the pioneering work of Johnson [37], shows that, basically, only in the 1990s, case studies started appearing. However, they were still quite simple and shy. This was also observed in this study. The case studies considering more realistic variables emerged only from the year 2000 onwards, slowly evolving to become more frequent in recent years.

All the studies analyzed here addressed industrial manufacturing environments (with physical products), that is, no case study papers for service companies were found. An application in service can be exemplified in [79], an engineering consultancy firm is compared to two parallel flow shops. However, it is not a case study and therefore not considered in our sample.

Another research potential identified is the almost absence of real case publications in the field of green scheduling, which involves production planning problems aimed at minimizing energy consumption in industries. The three papers included in the sample Refs. $[14,85,88]$ were all published in the year 2016 . Other examples of green scheduling (out of this sample) are: Refs. $[22,48,19,53]$ that consider the flow shop problem; Ref. [51] that consider the hybrid flow shop problem; Refs. [49,95] that studies job shops; and Ref. [75] that models the problem as that of a single machine. The aforementioned are experimental studies that do not use real data nor do they mention any practical business applications.

It came as a surprise that, although uncertainty is a common feature in real life problems, all the case studies included in the sample addressed the problem from a deterministic point of view. This highlights another important gap that should be reduced in future research. Recent papers, such as Refs. [35,6,20,80], treat uncertainty under different points of views. Huang and Liao [35] propose an agent-based multi-negotiation mechanism approach to solve a parallel machines scheduling problem in the manufacturing processes of aluminum foil. Aydilek et al. [6] also address uncertain processing times. The manufacturing environment consists of a single machine and the optimization criterion is the minimization of tardy jobs. Only lower and upper bounds for the processing times of each job are considered known. Several versions of an algorithm, based on dominance relation, are proposed to provide a solution that will perform well for any combination of feasible realizations of processing times. Intervals for the job processing times are also considered by Drwal and Rischke [20]. They study the computational complexity of the scheduling problem on parallel identical machines. To cope with the uncertainty, they consider the maximum regret and prove that its minimization is strongly NP-hard. Tchernykh et al. [80] discuss a variety of types and sources of uncertainty associated with cloud computing. Approaches for the optimization of related problems are reviewed and aims at finding solutions that behave good and insensitive to different uncertainties. Pinedo [60] presents several issues related to stochastic models considering single machine, 
Table 6

Number of researchers by country and year (in decreasing order of frequency).

\begin{tabular}{|c|c|c|c|c|c|c|c|c|c|c|c|c|c|c|c|c|c|c|}
\hline Country & 1992 & 1993 & 1998 & 2002 & 2003 & 2004 & 2005 & 2006 & 2007 & 2009 & 2010 & 2011 & 2012 & 2013 & 2014 & 2015 & 2016 & Total \\
\hline China & & & & & & & & & & & 4 & & & 2 & 3 & 4 & 15 & 28 \\
\hline Spain & & & & & & & 5 & 2 & & 2 & 2 & 4 & 2 & & & & & 17 \\
\hline Taiwan & & & & & 2 & & & & & & & & 4 & 5 & & 2 & & 13 \\
\hline France & & & & & & & & & 1 & & 4 & & 3 & & & & 2 & 10 \\
\hline USA & & & & 1 & & 3 & & & & & & & & & & & 6 & 10 \\
\hline Brazil & & & & & & & & & & & & 3 & & & 4 & & & 7 \\
\hline Japan & & 4 & & 3 & & & & & & & & & & & & & & 7 \\
\hline Germany & & & 2 & & & & & & & & & & & & 4 & & & 6 \\
\hline Hong Kong & & & & & & & & 6 & & & & & & & & & & 6 \\
\hline Italy & 2 & & & & & & & & & & & & & & & 3 & & 5 \\
\hline South Korea & & & & & & & & & & & & 3 & & & & 2 & & 5 \\
\hline Tunisia & & & & & & & & & 3 & & & & & & & & 2 & 5 \\
\hline Poland & & & & & & & & & & & & & 1 & 3 & & & & 4 \\
\hline Australia & & & & & & & & & & & & & & & & 3 & & 3 \\
\hline Indonesia & & & & & & & & & & & & & & & & 3 & & 3 \\
\hline Morocco & & & & & & & & & & & & & & & & & 3 & 3 \\
\hline Belgium & & & & & & & & & 2 & & & & & & & & & 2 \\
\hline Iceland & & & & & & & & & & & & 2 & & & & & & 2 \\
\hline India & & & & & & & & & & & & & & & 2 & & & 2 \\
\hline Iran & & & & & & & & & & & & & & & & & 2 & 2 \\
\hline UK & & & & & & & & & & & & 1 & & & 1 & & & 2 \\
\hline Thailand & & & & & & & & & & & 2 & & & & & & & 2 \\
\hline Argentina & & & & & & & & & & & 1 & & & & & & & 1 \\
\hline Greece & & & & & & & & & & & & & 1 & & & & & 1 \\
\hline Singapore & & & & & & & & & & & & & & & 1 & & & 1 \\
\hline Total & 2 & 4 & 2 & 4 & 2 & 3 & 5 & 8 & 6 & 2 & 13 & 13 & 11 & 10 & 15 & 17 & 30 & \\
\hline
\end{tabular}

parallel machines, flow shops, job shops and open shops environments.

All the features mentioned in this section were collected by detailed analysis of the content of each paper because, of course, there was no standardization in the research methodology used by the researchers of the publications, even though they all deal specifically with case studies. Some information was not explicit, such as the number of stages of a hybrid flow shop system in some papers or the time horizon considered when collecting research data. However, no omission compromised the analysis nor the contribution made to this study.

This analysis showed the complexity of the problems and practical situations involving production scheduling as well as the variety of possible solution methods. And, as expected, there is no single method that solves all kinds of problems. Thus, to tackle industrial problems, as pointed out in Ref. [32], it is crucial that companies make available real problems to the scientific community and help evaluate the results according to the appropriate performance indices. It is also important that researchers assess the applicability of the methods to ensure fast solutions for large and complex problems and that both communities (industrial and researchers) unite their projects to merge methodologies for collaborative solutions.

This study confirms these issues and endorses the argument that they can shed light on the current challenges, thus reducing the gap between theory and practice. It is strongly suggested, therefore, the strengthening of relations and the joint work of business people and academics, uniting efforts in the same direction to produce the results and also products equally needed by both.

\section{Final considerations}

This work presents a mapping of publications in indexed journals of case studies in production scheduling. A sample of 46 papers published between the years 1992-2016 was identified and analyzed. According to the classification of scheduling problems, the most studied was the hybrid flow shop problem, followed by flow shop and job shop systems. The problems of parallel machines, quite common in experimental research, were little discussed in case studies.
The 46 papers examined clearly show the applicability of optimization techniques to scheduling problems, in basic industries, processing industries and final assembly ones. On the other hand, there were no papers addressing service companies, such as project consulting, for example. Also, no case studies were found addressing uncertainty that is so common in real life problems. Few case studies were found following the current trend to reduce energy consumption and the resulting carbon dioxide emissions in the atmosphere, i.e. addressing the area called green scheduling. And so these are gaps in the literature found by this research.

Regarding the performance measures, the most widely used is the makespan or a related function. Moreover, most studies only consider one performance criterion, when in practice the companies are interested in several measures simultaneously. To solve the problems, non-exact methods were the most commonly used procedures and Mixed Integer Linear Programming models have also been proposed. It was found that none of the studies used any alternative exact solution technique, indicating a research gap.

On the main issue addressed in this work, which is the gap between theory and practice in production scheduling, the fact that the studies do not make reference to computer systems present in the companies seems indicative of incipient use. Their greater use could increase the practical application of the research results. On the other hand, the implementation of computer and automated systems can also be a limiting factor, as it depends on investment and acquisition of computer equipment and software, as well as training and technical support.

Finally, it appears that one of the main difficulties to reduce the gap between theory and practice is the difference between the timing of research and business. The scientific focus is on evidence and methodology, with subsequent publication subjected to rigorous peer evaluation. Companies, on the other hand, require quick, often empirical, solutions dispensing theoretical proof if the results are satisfactory and on time. Also there are confidentiality restrictions of data and the process itself.

In other words, the academics offer simulated solutions and need problems to apply them to, and companies need the solutions to the problems they face, but both in asynchronous rhythms. 
In this sense, more public interaction and partnership between researchers and managers is urged.

\section{Acknowledgements}

This work was partially supported by CNPq (306194/20120, 502547/2014-6, 443464/2014-6, 233654/2014-3), CAPES (BEX 2791/15-3), FAPESP (2013/07375-0, 2010/10133-0) and FAPEG (201510267000983) and was partially developed during the first author's postdoctoral activities in the University of New South Wales, Australia. The second author thanks the hospitality of the Universidad de Valladolid, Spain, where part of this work was conducted. The authors are also grateful to the organizing committee of the COMPSE 2016 conference and to the anonymous referees whose comments were important to enhance the paper quality and readability.

\section{References}

[1] A. Allahverdi, C.T. Ng, T.C.E. Cheng, M.Y. Kovalyov, A survey of scheduling problems with setup times or costs, Eur. J. Oper. Res. 187 (2008) 985-1032.

[2] B. Almada-Lobo, J.F. Oliveira, M.A. Carravilla, Production planning and scheduling in the glass container industry: a VNS approach, Int. J. Prod. Econ. 114 (2008) 363-375.

[3] R. Alvarez-Valdes, A. Fuertes, J.M. Tamarit, G. Giménez, R. Ramos, A heuristic to schedule flexible job-shop in a glass factory, Eur. J. Oper. Res. 165 (2005) 525-534.

[4] F.F. Alves, T.H. Nogueira, R.S. Henriques, P.V. Castro, Integrated lot sizing and production scheduling formulations: an application in a refractory cement industry, Gestão \& Produção 23 (1) (2016) 204-218.

[5] C. Artigues, P. Lopez, A. Haït, The energy scheduling problem: industrial case-study and constraint propagation techniques, Int. J. Prod. Econ. 143 (1) (2013) 13-23.

[6] A. Aydilek, H. Aydilek, A. Allahverdi, Algorithms for minimizing the number of tardy jobs for reducing production cost with uncertain processing times, Appl. Math. Modell. 45 (2017) 982-996.

[7] T.P. Bagchi, J.N.D. Gupta, C. Sriskandarajah, A review of TSP based approach for flowshop scheduling, Eur. J. Oper. Res. 169 (2006) 816-854

[8] K.R. Baker, Introduction to Sequencing and Scheduling, John Wiley \& Sons, New York, 1974.

[9] R. Belaïd, V. T'kindt, C. Esswein, Scheduling batches in flowshop with limited buffers in the shampoo industry, Eur. J. Oper. Res. 223 (2012) 560-572.

[10] F. Blömer, H.-O. Günther, Scheduling of a multi-product batch process in the chemical industry, Comput. Ind. 36 (1998) 245-259.

[11] H. Boukef, M. Benrejeb, P. Borne, A proposed Genetic Algorithm coding for flow-shop scheduling problems, Int. J. Comput. Commun. Control 2 (3) (2007) 229-240.

[12] W. Bożejko, J. Pempera, C. Smutnicki, Parallel tabu search algorithm for the hybrid flow shop problem, Comput. Ind. Eng. 65 (2013) 466-474

[13] Cambrige Dictionary, www.dictionary.cambridge.org, (Access in 05 January 2017).

[14] A. Che, Y. Zeng, K. Lyu, An efficient greedy insertion heuristic for energy-conscious single machine scheduling problem under time-of-use electricity tariffs, J. Clean. Prod. 129 (2016) 565-577.

[15] J.C. Chen, C.-C. Wu, C.-W. Chen, K.-H. Chen, Flexible job shop scheduling with parallel machines using Genetic Algorithm and Grouping Genetic Algorithm, Expert Syst. Appl. 39 (2012) 10016-10021.

[16] Y.-Y. Chen, C.-Y. Cheng, L.-C. Wang, T.-L. Chen, A hybrid approach based on the variable neighborhood search and particle swarm optimization for parallel machine scheduling problems -a case study for solar cell industry, Int. J. Prod. Econ. 141 (2013) 66-78.

[17] T.C.E. Cheng, C.C.S. Sin, A state-of-the-art review of parallel-machine scheduling research, Eur. J. Oper. Res. 47 (3) (1990) 271-292.

[18] H.-S. Choi, J.-S. Kim, D.-H. Lee, Real-time scheduling for reentrant hybrid flow shops: a decision tree based mechanism and its application to a TFT-LCD line, Expert Syst. Appl. 38 (2011) 3514-3521.

[19] J.-Y. Ding, S. Song, C. Wu, Carbon-efficient scheduling of flow shops by multi-objective optimization, Eur. J. Oper. Res. 248 (2016) 758-771.

[20] M. Drwal, R. Rischke, Complexity of interval minmax regret scheduling on parallel identical machines with total completion time criterion, Oper. Res. Lett. 44 (2016) 354-358.

[21] M. Eddaly, B. Jarboui, P. Siarry, Combinatorial particle swarm optimization for solving blocking flowshop scheduling problem, J. Comput. Des. Eng. 3 (2016) 295-311.

[22] K. Fang, N. Uhan, F. Zhao, J.W. Sutherland, A new approach to scheduling in manufacturing for power consumption and carbon footprint reduction, J. Manuf. Syst. 30 (2011) 234-240.

[23] D. Ferreira, R. Morabito, S. Rangel, Solution approaches for the soft drink integrated production lot sizing and scheduling problem, Eur. J. Oper. Res. 196 (2) (2009) 697-706
[24] J.M. Framinan, J.N.D. Gupta, R. Leisten, A review and classification of heuristics for permutation flow-shop scheduling with makespan objective, J. Oper. Res. Soc. 55 (2004) 1243-1255.

[25] H.Y. Fuchigami, S. Rangel, Uma análise de estudos de casos em sequenciamento da produção, Simpósio Brasileiro de Pesquisa Operacional 46 (2014).

[26] T. Gawroński, Optimization of setup times in the furniture industry, Ann. Oper. Res. 201 (2012) 169-182.

[27] R. Gedik, C. Rainwater, H. Nachtmann, E.A. Pohl, Analysis of a parallel machine scheduling problem with sequence dependent setup times and job availability intervals, Eur. J. Oper. Res. 251 (2) (2016) 640-650.

[28] C.H. Glock, Decision support models for managing returnable transport items in supply chains: a systematic literature review, Int. J. Prod. Econ. 183 (2017) 561-569.

[29] R.L. Graham, E.L. Lawler, J.K. Lenstra, A.H.G. Rinnooy Kan, Optimization and approximation in deterministic sequencing and scheduling: a survey, Ann. Discrete Math. 5 (1979) 287-326.

[30] Z.X. Guo, W.K. Wong S.Y.S. Leung, J.T. Fan, S.F. Chan, Mathematical model and genetic optimization for the job shop scheduling problem in a mixed- and multi-product assembly environment: a case study based on the apparel industry, Comput. Ind. Eng. 50 (2006) 202-219.

[31] J.N.D. Gupta, E.F. Stafford Jr., Flowshop scheduling research after five decades, Eur. J. Oper. Res. 169 (2006) 699-711

[32] I. Harjunkoski, C.T. Maravelias, P. Bongers, P.M. Castro, S. Engell, I.E. Grossmann, J. Hooker, C. Méndez, G. Sand, J. Wassick, Scope for industrial applications of production scheduling models and solutions methods, Comput. Chem. Eng. 62 (2014) 161-193.

[33] R.P. Hastuti, H. Yuliando, I.W.F. Aziz, Production scheduling using mixed integer programming: a case of bread small and medium enterprise at Yogyakarta, Agric. Agric. Sci. Procedia 3 (2015) 211-215.

[34] F.T. Hecker, M. Stanke, T. Becker, B. Hitzmann, Application of a modified GA, ACO and a random search procedure to solve the production scheduling of a case study bakery, Expert Syst. Appl. 41 (2014) 5882-5891.

[35] C.-J. Huang, L.-M. Liao, Parallel machines scheduling with machine preference via agent-based approach, Appl. Math. Comput. 233 (2014) 298-309.

[36] Z.H. Jin, K. Ohno, T. Ito, S.E. Elmaghraby, Scheduling hybrid flowshops in printed circuit board assembly lines, POMS Ser. Technol. Oper. Manage. 11 (2002) 216-230.

[37] S.M. Johnson, Optimal two- and three-stage production schedules with setup times included, Naval Res. Logist. Q. 1 (1954) 61-68.

[38] S. Jun, J. Park, A hybrid genetic algorithm for the hybrid flow shop scheduling problem with nigthttime work and simultaneous work constraints: a case study from the transformer industry, Expert Syst. Appl. 42 (2015) 6196-6204

[39] H. Kong, E. Qi, S. He, G. Li, MILP model for plant-wide optimal by-product gas scheduling in iron and steel industry, J. Iron Steel Res. 17 (7) (2010) 34-37.

[40] G.M. Kopanos, C.A. Méndez, L. Puigjaner, MIP-based decomposition strategies for large-scale scheduling problems in multiproduct multistage batch plants: a benchmark scheduling problems of the pharmaceutical industry, Eur. J. Oper. Res. 207 (2010) 644-655.

[41] G.M. Kopanos, L. Puigjaner, M.C. Georgiadis, Efficient mathematical frameworks for detailed production scheduling in food processing industries, Comput. Chem. Eng. 42 (2012) 206-216.

[42] R. Landmann, R.H. Erdmann, Uma abordagem heurística para a programação da produção na indústria de fundição com utilização da lógica fuzzy, Gestão Produção 18 (1) (2011) 119-130.

[43] D. Lei, Multi-objective production scheduling: a survey, Int. J. Adv. Manuf. Technol. 43 (2009) 926-938.

[44] J. Li, Y. Huang, X. Niu, A branch population genetic algorithm for dual-resource constrained job shop scheduling problem, Comput. Ind. Eng. 102 (2016) 113-131.

[45] J.-Q. Li, Q.-K. Pan, K. Mao, P.N. Suganthan, Solving the steelmaking casting problem using an effective fruit fly optimization algorithm, Knowl.-Based Syst. 72 (2014) 28-36.

[46] H.-T. Lin, C.-J. Liao, A case study in a two-stage hybrid flow shop with setup time and dedicated machines, Int. J. Prod. Econ. 86 (2003) 133-143.

[47] J.T. Lin, C.-M. Chen, Simulation optimization approach for hybrid flow shop scheduling problem in semiconductor back-end manufacturing, Simul. Modell. Pract. Theory 51 (2015) 100-114.

[48] G.-S. Liu, B.-X. Zhang, H.-D. Yang, X. Chen, G.Q. Huang, A branch-and-bound algorithm for minimizing the energy consumption in the PFS problem, Math. Prob. Eng. 2013 (2013) 1-6.

[49] Y. Liu, H. Dong, N. Lohse, S. Petrovic, N. Gindy, An investigation into minimizing total energy consumption and total weighted tardiness in job shops, J. Clean. Prod. 65 (2014) 87-96.

[50] T. Loukil, J. Teghem, P. Fortemps, A multi-objective production scheduling case study solved by simulated annealing, Eur. J. Oper. Res. 179 (2007) 709-722.

[51] H. Luo, B. Du, G.Q. Huang, H. Chen, X. Li, Hybrid flow shop scheduling considering machine electricity consumption cost, Int. J. Prod. Econ. 146 (2013) 423-439.

[52] B.L. MacCarthy, J.Y. Liu, Addressing the gap in scheduling research ?a review of optimization and heuristic methods in production scheduling, Int. J. Prod. Res. 31 (1) (1993) 59-79.

[53] S.A. Mansouri, E. Aktas, U. Besikci, Green scheduling of a two-machine flowshop: trade-off between makespan and energy consumption, Eur. J. Oper. Res. 248 (2016) 772-788. 
[54] M.K. Marichelvam, T. Prabaharan, X.S. Yang, Improved cuckoo search algorithm for hybrid flow shop scheduling problems to minimize makespan, Appl. Soft Comput. 19 (2014) 93-101.

[55] A. Maroosi, R.C. Muniyandi, E. Sundararajan, A.M. Zin, A parallel membrane inspired harmony search for optimization problems: a case study based on a flexible job shop scheduling problem, Appl. Soft Comput. 49 (2016) 120-136.

[56] K. McKay, M. Pinedo, S. Webster, Practice-focused research issues for scheduling systems, Prod. Oper. Manage. 11 (2) (2002) 249-258.

[57] E. Mokotoff, Parallel machine scheduling problems: a survey, Asia-Pac. J. Oper. Res. 18 (1) (2001) 193-242.

[58] T.E. Morton, D.W. Pentico, Heuristic Scheduling Systems, John Wiley \& Sons, New York, 1993.

[59] P. Parthanadee, J. Buddhakulsomsiri, Simulation modeling and analysis for production scheduling using real-time dispatching rules: a case study in canned fruit industry, Comput. Electron. Agric. 70 (2010) 245-255.

[60] M.L. Pinedo, Scheduling: Theory, Algorithms, and Systems, fifth ed., Prentice-Hall, New Jersey, 2016

[61] N.D. Pizzolato, S.G.G. Vásquez, S.L.G. D’Ávila, O problema de sequenciamento da produção em uma indústria química: avaliação de uma aplicação real, Gestão Produção 6 (1) (1999) 16-29.

[62] C.N. Potts, V.A. Strusevich, Fifty years of scheduling: a survey of milestones, J. Oper. Res. Soc. 60 (2009) S41-S68.

[63] H. Qin, Z.-H. Zhang, D. Bai, Permutation flowshop group scheduling with position-based learning effect, Comput. Ind. Eng. 92 (2016) 1-15.

[64] H.F. Rahman, R. Sarker, D. Essam, A real-time order acceptance and scheduling approach for permutation flow shop problems, Eur. J. Oper. Res. 247 (2015) 488-503.

[65] D. Rahmani, R. Ramezanian, A stable reactive approach in dynamic flexible flow shop scheduling with unexpected disruptions: a case study, Comput. Ind. Eng. 98 (2016) 360-372.

[66] S. Reza Hejazi, S. Saghafian, Flowshop scheduling problems with makespan criterion: a review, Int. J. Prod. Res, 43 (14) (2005) 2895-2929.

[67] I. Ribas, R. Leisten, J.M. Framiñan, Review and classification of hybrid flow shop scheduling problems from a production system and a solution procedure perspective, Comput. Oper. Res. 37 (2010) 1439-1454.

[68] A. Rossi, S. Soldani, M. Lanzetta, Hybrid stage shop scheduling, Expert Syst. Appl. 42 (2015) 4105-4119.

[69] R. Ruiz, C. Maroto, A comprehensive review and evaluation of permutation flowshop heuristics, Eur. J. Oper. Res. 165 (2005) 479-494.

[70] R. Ruiz, C. Maroto, A genetic algorithm for hybrid flowshops with sequence dependent setup times and machine eligibility, Eur. J. Oper. Res. 169 (2006) $781-800$.

[71] R. Ruiz, J.A. Vázquez-Rodríguez, The hybrid flow shop scheduling problem, Eur. J. Oper. Res. 205 (2010) 1-18.

[72] P. Sandroni, Novíssimo Dicionário De Economia, Best Seller, São Paulo, 2000.

[73] O.B. Senties, C. Azzaro-Pantel, L. Pibouleau, S. Domenech, Multiobjective scheduling for semiconductor manufacturing plants, Comput. Chem. Eng. 34 (2010) 555-566.

[74] P. Serafini, M.G. Speranza, Production scheduling problems in a textile industry, Eur. J. Oper. Res. 58 (1992) 173-190.

[75] F. Shrouf, J. Ordieres-Meré, A. García-Sánchez, M. Ortega-Mier, Optimizing the production scheduling of a single machine to minimize total energy consumption costs, J. Clean. Prod. 67 (2014) 197-207.

[76] B.J.V. Silva, R. Morabito, D.S. Yamashita, H.H. Yanasse, Production scheduling of assembly fixtures in the aeronautical industry, Comput. Ind. Eng. 67 (2014) 195-203.

[77] B.J.V. Silva, R. Morabito, H.H. Yanasse, Production scheduling of assembly fixtures with adjacent constraints in the aeronautics industry, Produção 21 (4) (2011) 696-707.

[78] H. Stefansson, S. Sigmarsdottir, P. Jensson, N. Shah, Discrete and continuous time representations and mathematical models for large production scheduling problems: a case study from the pharmaceutical industry, Eur. J. Oper. Res. 215 (2011) 383-392.

[79] P.S. Sundararaghavan, A.S. Kunnathur, I. Viswanathan, Minimizing makespan in parallel flowshops, J. Oper. Res. Soc. 48 (1997) 834-842.

[80] A. Tchernykh, U. Schwiegelsohn, E. Talbi, M. Babenko, Towards understanding uncertainty in cloud computing with risks of confidentiality, integrity, and availability, J. Comput. Sci. (2016), published online.
[81] A. Touil, A. Echchatbi, A. Charkaoui, An MILP model for scheduling multistage, multiproducts milk processing, IFAC-Pap. On Line 49 (12) (2016) 869-874.

[82] M. Tsubone, H. Ohba, A production scheduling system for a hybrid flow shop -a case study, OMEGA Int. J. Manage. Sci. 21 (2) (1993) 205-214.

[83] J.C. Vidal, M. Mucientes, A. Bugarín, M. Lama, Machine scheduling in custom furniture industry through neuro-evolutionary hybridization, Appl. Soft Comput. 11 (2011) 1600-1613.

[84] I.R. Vila, R.C. Pascual, A hybrid flow shop model for an ice cream production scheduling problem, J. Ind. Eng. Manage. 2 (1) (2009) 60-89.

[85] S. Wang, M. Liu, F. Chu, C. Chu, Bi-objective optimization of a single machine batch scheduling problem with energy cost consideration, J. Clean. Prod. 137 (2016) 1205-1215

[86] A.D. Wilson, R.E. King, T.J. Hodgson, Scheduling non-similar groups on a flow line: multiple group setups, Rob. Comput. Integr. Manuf. 20 (2004) 505-515.

[87] B. Yagmahan, M.M. Yenisey, Scheduling practice and recent development in flow shop and job shop scheduling, Computational Intelligence in Flow Shop and Job Shop Scheduling SCI230 (2009) 261-300.

[88] J. Yan, L. Li, F. Zhao, F. Zhang, Q. Zhao, A multi-level optimization approach for energy-efficient flexible flow shop scheduling, J. Clean. Prod. 137 (2016) 1543-1552.

[89] T. Yang, An evolutionary simulation optimization approach in solving parallel-machine scheduling problems: a case study, Comput. Ind. Eng. 56 (3) (2009) 1126-1136.

[90] J.-H. Yang, J.-J. Cai, W.-Q. Sun, J.Y. Liu, Optimization and scheduling of byproduct gas system in steel plant, J. Iron Steel Res. 22 (5) (2015) 408-413.

[91] L. Yu, H.M. Shih, M. Pfund, W.M. Carlyle, J.W. Fowler, Scheduling of unrelated parallel machines: an application to PWB manufacturing, IIE Trans. 34 (11) (2002) 921-931.

[92] S. Yu, K. Li, Y. Xu, A DAG task scheduling scheme on heterogeneous cluster systems using discrete IWO algorithm, J. Comput. Sci. (2016), in press.

[93] Y. Zhang, G.Q. Huang, S. Sun, T. Yang, Multi-agent based real-time production scheduling method for radio frequency identification enabled ubiquitous shopfloor environment, Comput. Ind. Eng. 76 (2014) 89-97.

[94] R. Zhang, P.-C. Chang, C. Wu, A hybrid genetic algorithm for the job shop scheduling problem with practical considerations for manufacturing costs: investigations motivated by vehicle production, Int. J. Prod. Econ. 145 (2013) $38-52$.

[95] R. Zhang, R. Chiong, Solving the energy-efficient job shop scheduling problem: a multi-objective genetic algorithm with enhanced local search for minimizing the total weighted tardiness and total energy consumption, J. Clean. Prod. 112 (2016) 3361-3375.

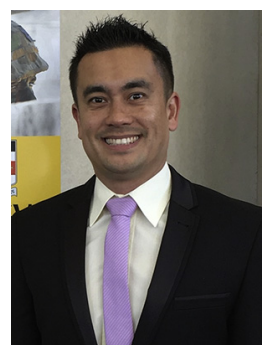

Helio Yochihiro Fuchigami received the Ph.D. in Production Engineering in 2010 and the M.Sc. in Production Engineering in 2005, both from University of Sao Paulo, Brazil. He has visiting the Polytechnic University of Valencia, Spain, in 2007, and University of New South Wales, Australia, in 2015. Now he is adjunct professor of Production Engineering of Federal University of Goias, Brazil. His major research includes Operational Research, production scheduling and heuristics.



Socorro Rangel is an associate professor in Operational Research at UNESP, Brazil. She received her PhD at Brunel University, England in 1996. Since then she has been mainly involved in the study of large-scale combinatorial optimization problems. The focus has been on building efficient models for practical applications, and developing solving techniques based on hybrid algorithms that combine several methods such as partial enumeration, cutting planes, heuristics, pre-processing and aggregation/decomposition. Recently, she has been involved in modelling and solving production planning problems in soft drink and furniture industry. 